\title{
Maternal Endotoxin-Induced Preterm Birth in Mice: Fetal Responses in Toll-Like Receptors, Collectins, and Cytokines
}

\author{
ANNAMARI SALMINEN, REIJA PAANANEN, REETTA VUOLTEENAHO, JUHANI METSOLA, MARJA OJANIEMI, \\ HELENA AUTIO-HARMAINEN, AND MIKKO HALLMAN \\ Department of Pediatrics [A.S., R.P., R.V., J.M., M.O., M.H.] and Department of Pathology [H.A.-H.], \\ University of Oulu, Oulu, FIN-90014, Finland
}

\begin{abstract}
Major cause of prematurity is spontaneous preterm birth (PTB) associated with intrauterine inflammation. Our aim was to establish a model of endotoxin Lipopolysaccharide-induced PTB of live-born pups and to study early immune activation in fetal and maternal compartments. Expression of several proteins that bind microbes (Toll-like receptors TLR4, TLR2; surfactant proteins SP-A, SP-D) was analyzed. At 16 or $17 \mathrm{~d}$ of gestation, C57BL/6 dams received a single dose of intraperitoneal LPS, leading to PTB within $17 \mathrm{~h}$. Cytokine levels increased in maternal serum, followed by a modest increase in fetal serum and in amniotic fluid. In uterus, placenta, and fetal membranes, LPS mostly increased the expressions of TLR, SPs, and cytokines. The number of TLR2-positive macrophages increased in labyrinthine placenta. In fetal lung, intestine, liver, and brain there were modest changes in cytokine expressions. In fetal lung, SP and TLR mRNAs decreased and TLR2-positive macrophages redistributed around vessels. LPS-induced fetal deaths associated with early age (16 d gestation) rather than with proinflammatory activation. Here we propose that maternal LPS response leads to PTB and acute decrease of immune proteins in epithelial lining of fetal lung. Instead, acceleration of lung maturity has been previously observed in intraamniotic inflammation. (Pediatr Res 63: 280-286, 2008)
\end{abstract}

$\mathrm{P}$ rematurity is the main cause of perinatal morbidity and mortality in developed countries. Altogether, $50-70 \%$ of preterm births (PTBs) in humans are due to spontaneous onset of premature labor (1). There is a strong relationship between systemic or intrauterine infection and preterm delivery. Lipopolysaccharide (LPS), an endotoxin of Gram-negative bacteria, causes PTB in animals and has been implicated as a factor triggering preterm labor in humans (2). Different model systems have been established to study the induced PTB in mammalian species $(3,4)$. The inflammatory models applied to mice involve intraperitoneal, intrauterine, or intraamniotic administration of heat-killed bacteria or bacterial products (5-7). Depending on the dose, gestational age, and site of exposure, the consequences of LPS-induced inflammatory response are

Received August 7, 2007; accepted November 1, 2007.

Correspondence: Annamari Salminen, Department of Pediatrics, P.O. Box 5000, University of Oulu, FIN-90014, Finland; e-mail: annamari.salminen@oulu.fi

Supported by Sigrid Juselius Foundation, Biocenter Oulu, and Foundation for Pediatric Research, Finland.

R.P. and R.V. contributed equally to this work.

Presented at the ATS meeting April 2007 in San Francisco (Am J Resp Crit Care Med 175;A888, 2007). variable. However, the administration of LPS has mostly resulted in fetal death or the delivery of dead fetuses (6-11).

The proposed sequence of inflammatory mediators leading to preterm labor and delivery involves the production of proinflammatory cytokines in uterus, placental tissue, and fetal tissues as a response to bacterial toxins. The cytokines, in turn, initiate the synthesis of secondary mediators, e.g., prostaglandins and matrix metalloproteinases involved in the preterm delivery $(2,4)$. It has been proposed that fetal death results from a maternal response rather than fetal sensitivity to LPS $(12,13)$.

The innate immune system involved in nonclonal host defense is likely to influence fetal outcome. Toll-like receptors (TLRs) and collectins serve as signaling receptors for pathogen-associated molecular patterns and they interactively influence the inflammatory response (14). LPS induces an inflammatory response by binding to TLR4, together with CD14 and MD-2 (15). Activation of TLR4 triggers a complex signaling cascade that leads to activation of transcription factors, particularly nuclear factor, $\kappa \mathrm{B}$ and upregulation of other TLRs, pro- and antiinflammatory cytokines and chemokines, and other inflammatory mediators $(16,17)$.

The surfactant proteins A (SP-A) and D (SP-D) are collectins that bind various microbes serving as agglutinins, opsonins, and immunomodulators (18). Although SP-A and SP-D are synthesized in alveolar epithelium and influence the homeostasis of the surfactant system (14), they are expressed in other tissues as well $(19,20)$. SP-D is present in the female reproductive tract (21) and SP-A and SP-D in amniotic fluid (22), suggesting that these proteins may also participate in intrauterine inflammatory responses. In addition, SP-A has been suggested to be the labor-inducing signal secreted by the fetal lung (23).

The aim of the present project was to establish a mouse model of spontaneous PTB following maternal LPS challenge and to identify the responding tissues. We propose that the route of entry of the labor-inducing inflammatory signal into the intrauterine compartment may critically influence the fetal outcome.

\footnotetext{
Abbreviations: dpc, days post coitum; LPS, lipopolysaccharide; MCP-1, monocyte chemoattractant protein-1; MIP-2, macrophage inflammatory protein-2; PTB, preterm birth; SP, surfactant protein; TLR, Toll-like receptor
} 


\section{MATERIALS AND METHODS}

Animals. Timed-pregnant C57BL/6 and FVB mice were used. The strains were chosen after preliminary analysis of LPS response using six different mouse strains. Gestational age $( \pm 12 \mathrm{~h})$ was determined by the presence of vaginal plug and designated as day 0 of pregnancy. All studies were approved by the Animal Research Committee of the University of Oulu.

Mouse model of preterm birth. The gestational ages (16 and $17 \mathrm{~d}$ of pregnancy) used in the present study coincide with the transition from the canalicular to the saccular stage of lung development, corresponding to 23-27 wk in human lung development $(24,25)$. The mice were intraperitoneally (i.p.) injected at 16 or $17 \mathrm{~d}$ post coitum (dpc) with PBS or purified Escherichia coli LPS (serotype 0111:B4, Sigma Chemical Co., St. Louis, MO) dissolved in PBS. Based on previous publications $(3,4)$, doses of $10-50 \mu \mathrm{g} /$ mouse $(0.4-2$ $\mathrm{mg} / \mathrm{kg})$ were used in preliminary studies and $25 \mu \mathrm{g} /$ mouse $(\sim 1 \mathrm{mg} / \mathrm{kg})$ was chosen for the experiments.

To study the pregnancy outcomes, C57BL/6 dams were injected i.p. with 25 $\mu \mathrm{g} /$ mouse of LPS on day $16(n=13)$ or $17(n=32)$ of gestation. Control dams received an equal volume of sterile PBS i.p. $(n=31)$. For the FVB strain, 19 dams were injected with PBS and 44 dams with LPS at $16 \mathrm{dpc}(n=18)$ or $17 \mathrm{dpc}$ $(n=26)$. The dams were followed every $4 \mathrm{~h}$ during first $12 \mathrm{~h}$ after injection and then continuously until the time of delivery. Following LPS, the dams showed no evidence of serious disease. The viability of the prematurely born pups was observed after birth continuously for $2 \mathrm{~h}$, then every $15 \mathrm{~min}$ for up to $6 \mathrm{~h}$ after birth. In cases of severe respiratory failure, pups were euthanized. A litter was called live-born when $\geq 50 \%$ of the pups were born alive.

Sample collection. For protein and mRNA analysis, C57BL/6 dams were injected as described above. The dams were anesthetized with ketaminemedetomidine 1,3 , or $8 \mathrm{~h}$ after PBS or LPS injections $(n=7-11)$, blood samples from orbital sinus were collected, and the mice were killed with cervical dislocation. In each group, 5-11 dams or their litters were examined and 2-4 pups from every litter were analyzed individually. Amniotic fluid, blood from decapitated fetuses and fetal tissues (lung, heart, liver, brain, and intestine), fetal membranes (amnion and yolk sac), placenta, uterus (myometrium and endometrium), and maternal lung were harvested. The tissues were frozen in liquid nitrogen or fixed in $4 \%$ formaldehyde.

Cytometric bead array. The cytometric bead array (CBA) mouse inflammation kit (BD Biosciences; San Diego, CA) was used to measure the concentrations of TNF- $\alpha$, monocyte chemoattractant protein-1 (MCP-1), IL-10, and IL-6 from serum and amniotic fluid according to the manufacturer's instructions using FACSCalibur flow cytometer and the BD CBA software (BD Biosciences). An internal control sample was included in CBA assays. The interassay variation was 0.07 .

RNase protection assay. Total RNA from harvested tissues was isolated using Tri-reagent (Sigma Chemical Co.) according to the manufacturer's instructions. The mouse custom-designed multi-probe RNase protection assay (RPA) system (BD Biosciences) was used to quantitatively determine the expression levels of SP-A, SP-D, TLR4, TLR2, IL-1 $\beta$, macrophage inflammatory protein-2 (MIP-2),
IL-4, TNF- $\alpha$, IL-6, and IL-10 according to the manufacturer's protocol. In addition, the expression of the housekeeping gene L32 was analyzed as a reference. Positive and negative controls supplied by the manufacturer and an internal control sample were included in analysis. The quantity of protected fragments was analyzed by phosphoimaging (Quantity one, BioRad, Hercules, $\mathrm{CA}$ ). The normalized gene expression levels are shown as fold increase after LPS injection compared with controls injected with PBS.

Immunohistochemistry. Tissue sections were embedded in paraffin and cut into $5 \mu \mathrm{m}$ sections. Deparaffinized sections were heated in citrate-phosphate buffer, $\mathrm{pH} 6$, and incubated in peroxidase blocking solution (DAKO, Glostrup, Denmark) for $10 \mathrm{~min}$ at room temperature to remove endogenous peroxidase. After serial washes with PBS, the sections were blocked with donkey serum in PBS, and incubated with 1:100 dilution of anti-TLR4 or anti-TLR2 antibody (R\&D System Inc, Minneapolis, MN). Biotinylated secondary antibodies (Zymed Laboratories, San Francisco, CA) were detected with AB complex (DAKO) and stained with DAB substrate (DAKO).

The specificity of the TLR4 and TLR2 antibodies was confirmed using positive controls (blood monocytes) and tissue sections from TLR4 or TLR2 knock-out mice in which no staining was detected with current method.

Statistical analysis. The protein concentrations and mRNA values were statistically analyzed using Origin 7.0 and SPSS (SPSS Inc. version 12.0.1). The data were tested for normal distribution, and statistical significances between the controls and the LPS groups were analyzed using either $t$ test or Mann-Whitney $U$ test.

\section{RESULTS}

Preterm delivery of live-born pups following maternal LPS. The length of pregnancy in control C57BL/6 or FVB mice injected with PBS was $19-20 \mathrm{~d}$ or $18-20 \mathrm{~d}$, respectively (Table 1). To study the dose dependency of the induction of PTB of live offspring, timed-pregnant C57BL/6 and FVB dams were i.p. injected with $10-50 \mu \mathrm{g} / \mathrm{dam}$ of LPS on day 16 or 17 of gestation. Large doses of LPS $(>35 \mu \mathrm{g})$ resulted in delivery of stillborn fetuses within $24 \mathrm{~h}$, whereas low LPS doses $(\leq 20 \mu \mathrm{g})$ did not induce PTB (data not shown). LPS dose of $25 \mu \mathrm{g} / \mathrm{C} 57 \mathrm{BL} / 6$ dam at $17 \mathrm{dpc}$ induced PTB of mostly live-born pups $(58 \%)$ within $17 \mathrm{~h}( \pm 4 \mathrm{~h})$ (Table 1$)$. When labor was induced at $16 \mathrm{dpc}$, the interval from the LPS injection to delivery remained unchanged $(17 \mathrm{~h} \pm 3 \mathrm{~h})$. However, only $39 \%$ of the pups were born alive. The gestational age significantly associated with the fetal survival $(p<$

Table 1. Induction of preterm delivery by maternal LPS

\begin{tabular}{|c|c|c|c|c|c|c|c|}
\hline \multirow[b]{2}{*}{ Day } & \multirow[b]{2}{*}{ Litters/pups } & \multicolumn{3}{|c|}{ C57BL/6 strain } & \multicolumn{3}{|c|}{ FVB strain } \\
\hline & & LPS at $16 \mathrm{dpc}$ & LPS at $17 \mathrm{dpc}$ & Control $\dagger$ & LPS at $16 \mathrm{dpc}$ & LPS at $17 \mathrm{dpc}$ & Control $\dagger$ \\
\hline \multirow{3}{*}{17} & Total number of litters/pups & $13 / 84$ & $32 / 211$ & 31 & $18 / 140$ & $26 / 203$ & 19 \\
\hline & Litters born & $13(100) \ddagger$ & & & $12(67)$ & & \\
\hline & Live-born litters* & $5(38)$ & & & $2(11)$ & & \\
\hline \multirow{7}{*}{18} & Live-born pups & $33(39)$ & & & $17(12)$ & & \\
\hline & Stillborn litters & $8(62)$ & & & $10(56)$ & & \\
\hline & Stillborn fetuses & $51(61)$ & & & $70(50)$ & & \\
\hline & Litters born & - & $29(91)$ & $3(10)$ & $5(28)$ & $22(85)$ & $7(37)$ \\
\hline & Live-born litters* & - & $21(66)$ & $3(100)$ & $4(22)$ & $15(58)$ & $7(100)$ \\
\hline & Live-born pups & - & $122(58)$ & $(100)$ & $38(27)$ & $117(58)$ & (100) \\
\hline & Stillborn litters & - & $8(25)$ & - & $1(6)$ & $7(27)$ & - \\
\hline \multirow{3}{*}{19} & Stillborn fetuses & - & $67(32)$ & - & $7(5)$ & $51(15)$ & - \\
\hline & Litters bornII & - & $3(9)$ & $20(64)$ & $1(6)$ & $4(15)$ & $11(58)$ \\
\hline & Live-born litters* & - & $3(9)$ & $20(100)$ & $1(6)$ & $4(15)$ & $11(100)$ \\
\hline \multirow{3}{*}{20} & Live-born pups & - & $22(10)$ & (100) & $8(6)$ & $35(17)$ & (100) \\
\hline & Litters bornđI & - & - & $8(26)$ & - & - & $1(5)$ \\
\hline & Live-born litters* & - & - & $8(100)$ & - & - & $1(100)$ \\
\hline
\end{tabular}

* A litter is called live-born when $\geq 50 \%$ of the pups are born alive.

$\dagger$ Controls injected with PBS at 16 and $17 \mathrm{dpc}$.

$\$$ Values in parenthesis indicate percentages.

II No stillborn fetuses were detected among deliveries at 19 or $20 \mathrm{dpc}$. 

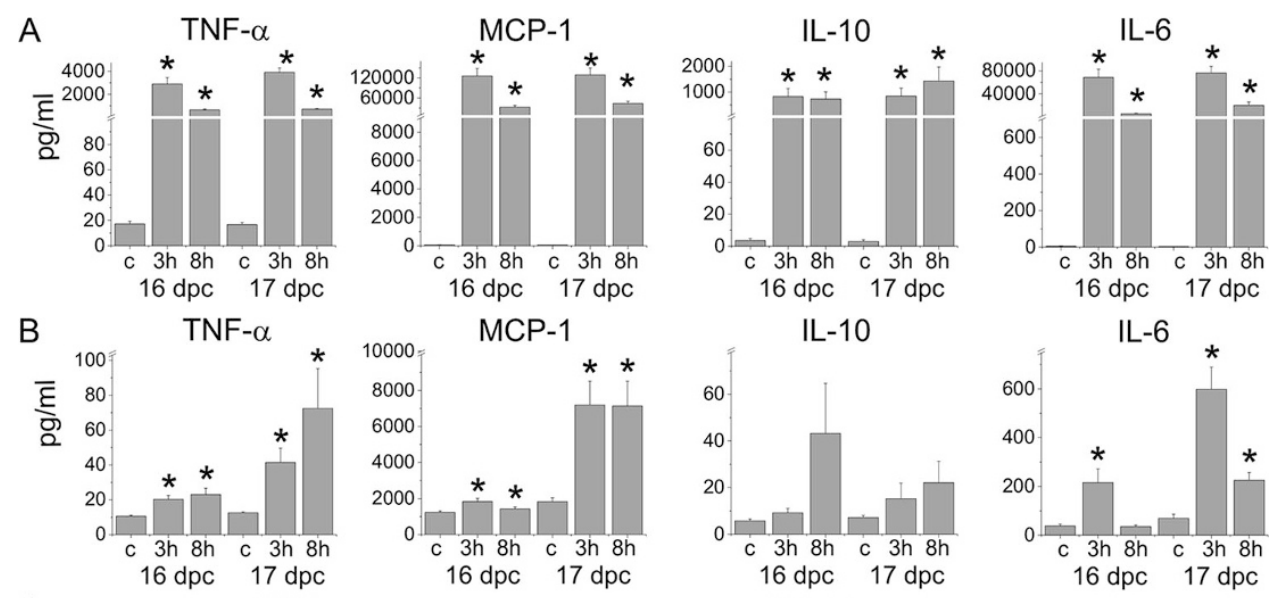

Figure 1. Acute cytokine response to maternal LPS. The concentrations of TNF- $\alpha$, MCP-1, IL-10, and IL-6 were measured in maternal serum $(A, C)$, amniotic fluid $(B$, $C$ ), and fetal serum $(C)$ using CBA. Cytokine concentrations are shown at 16 and 17 $\mathrm{dpc}$ both at 3 and $8 \mathrm{~h}$ after PBS (c = control) or LPS injections $(A, B)$. At 17 dpc, maternal (line with boxes) and fetal (line with triangles) sera and amniotic fluid (line with circles) were recovered 1, 3, or $8 \mathrm{~h}$ after PBS $(\mathrm{c}=$ control $)$ or LPS injection $(C)$. Analyses of 7-11 dams or their litters $(\mathrm{n}$ AF $=24-47, \mathrm{n}$ fetal serum $=$ $8-24)$ are shown as mean \pm SEM. Statistically significant inductions $(p<0.05)$ are denoted by $*$.
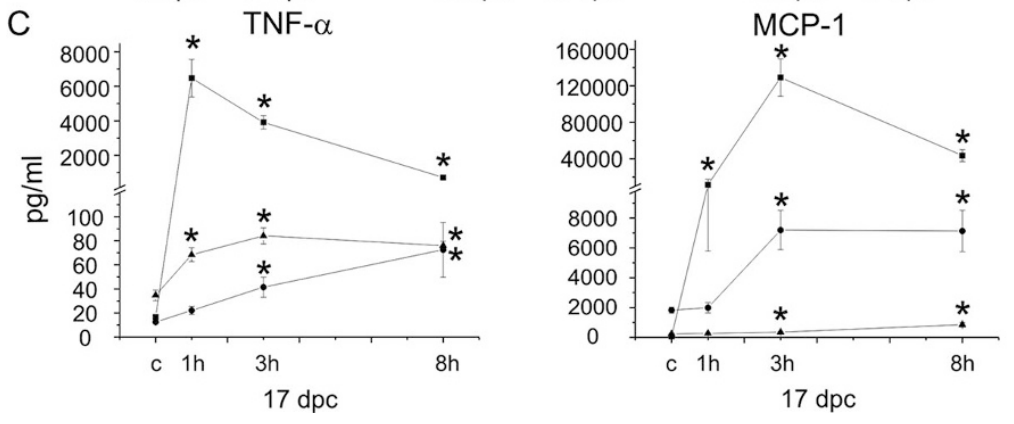

0.05). The pups born at $17 \mathrm{dpc}$ died of apparent respiratory failure within $30 \mathrm{~min}$, while the pups born alive at $18 \mathrm{dpc}$, survived up to several hours. In subsequent experiments, 25 $\mu \mathrm{g}$ LPS/dam was used.

LPS tended to increase PTBs also in the FVB strain (Table 1). However, the interval between the LPS injection and delivery $(20 \pm 4 \mathrm{~h})$ was longer than in the C57BL/6 strain. The proportion of live-born pups increased with gestational age also in the FVB strain. As almost $40 \%$ of the FVB control dams delivered already at $18 \mathrm{dpc}$, the difference in the time of birth between the LPS-induced and spontaneous deliveries was not significant. Therefore, C57BL/6 strain was chosen for further characterization of the inflammatory response associated with LPS-induced PTB.

Inflammatory mediators in maternal and fetal serum and in amniotic fluid. The maternal and fetal responses to LPS were evaluated by measuring cytokine concentrations in serum and amniotic fluid (Fig. 1). The concentrations of TNF- $\alpha$, MCP-1, IL-6, and IL-10 in maternal serum increased robustly and peaked at 1 or $3 \mathrm{~h}$ after LPS (Fig. 1A,C). All cytokine responses in fetal compartments were lower by more than one order of magnitude than those in the serum of the dam. In amniotic fluid, the concentrations of proinflammatory cytokines (TNF- $\alpha$, MCP-1, and IL-6) increased more slowly than in maternal serum and the changes in IL-10 were not significant (Fig. $1 B, C$ ).

To further study the effect of gestational age on LPSinduced immune responses, the cytokines in maternal blood and amniotic fluid were studied at 16 and $17 \mathrm{dpc}$ (Fig. 1). The length of gestation had no detectable influence on cytokines in maternal serum. In amniotic fluid, the control levels of cytokines were similar at 16 and $17 \mathrm{dpc}$. However, at $17 \mathrm{dpc}$ the responses in TNF- $\alpha$, MCP-1, and IL-6 were more prominent.
In fetal serum, TNF- $\alpha$ concentrations peaked $1-3 \mathrm{~h}$ after LPS, whereas the amount of MCP-1 remained low (Fig. 1C).

Expression of cytokines in fetal, placental, and maternal tissues. The expression of several inflammatory mediators was measured quantitatively by RPA. In fetal lung, heart, liver, brain, and intestine, only significant changes after maternal LPS were the increase in MIP-2 (analog of IL-8 in mice) mRNA in liver and the decrease in IL- $1 \beta$ expression in liver and intestine (Fig. 2).

In contrast to other fetal tissues, there was a distinct response in fetal membranes. At $17 \mathrm{dpc}$, both IL- $1 \beta$ and MIP-2 mRNAs were robustly induced at $3 \mathrm{~h}$, and the expressions

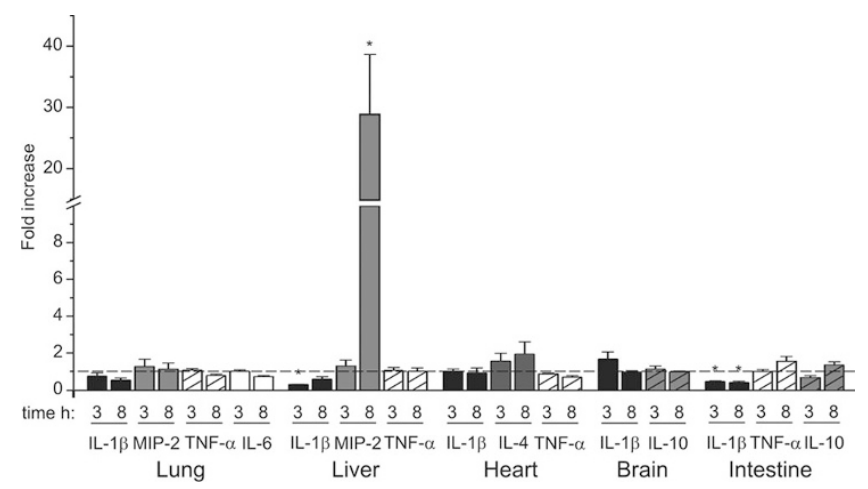

Figure 2. Inflammatory response in fetal tissues to maternal LPS. Fetal tissues were collected at $17 \mathrm{dpc} 3$ or $8 \mathrm{~h}$ after PBS $(n=4-6)$ or LPS $(n=$ $4-8$ ) injection. The mRNA levels of IL- $1 \beta$, MIP-2, IL-4, TNF- $\alpha$, IL-6, and IL-10 were analyzed by RPA and normalized to the expression level of the housekeeping gene L32. The mRNAs that could be quantified are shown as fold increases compared with controls that are shown with dash line. Analyses of 3-5 litters are shown as means \pm SEM. Statistically significant changes $(p<0.05)$ are denoted by $*$. 

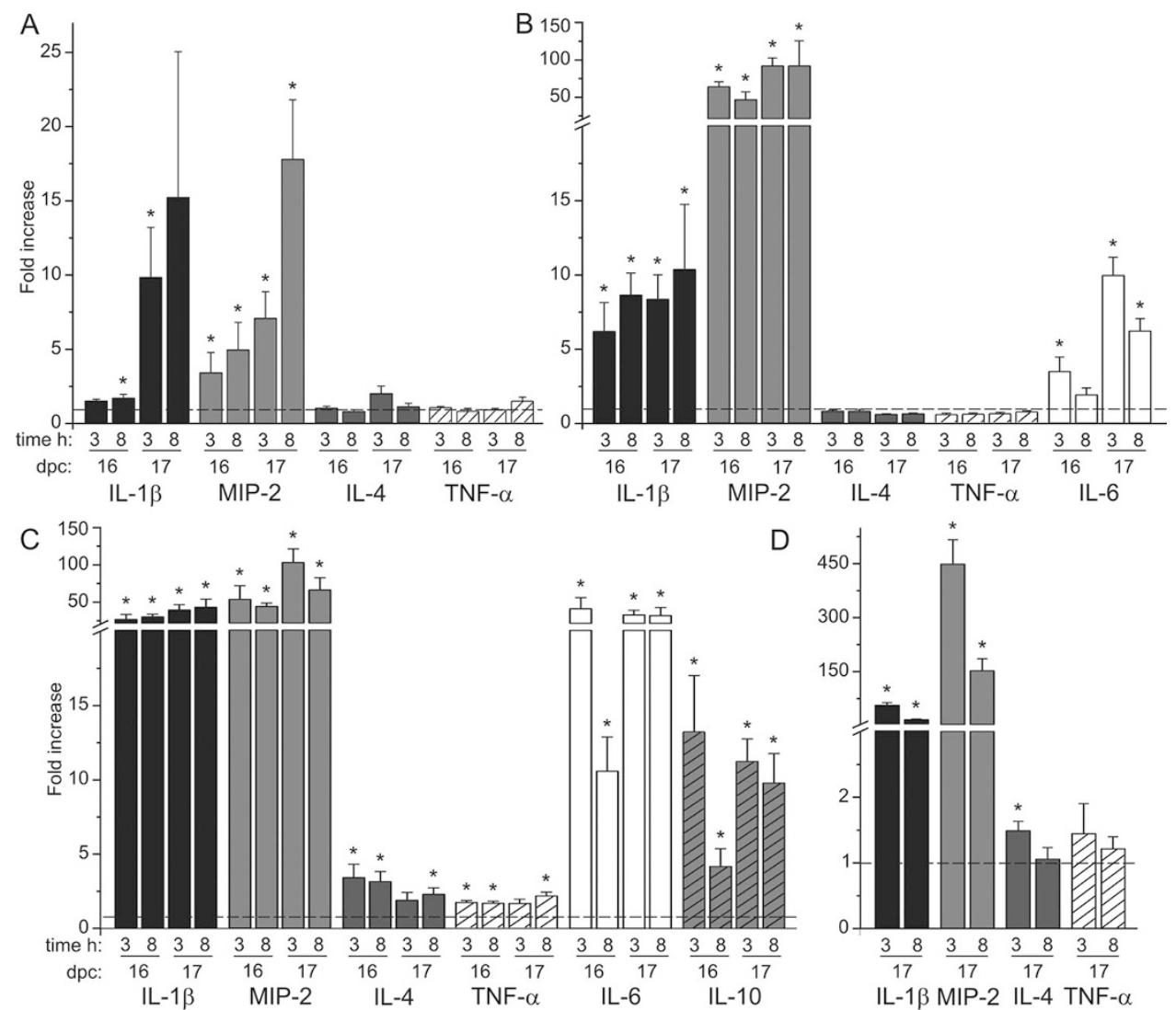

Figure 3. The cytokine response to maternal LPS in fetal membranes $(A)$, placenta $(B)$, uterus $(C)$, and maternal lung $(D)$. Tissues were collected at 16 or $17 \mathrm{dpc} 3$ or $8 \mathrm{~h}$ after PBS $(n=3-6)$ or LPS $(n=8)$ injection. The mRNA levels of IL- $1 \beta$, MIP-2, IL-4, TNF- $\alpha$, IL-6, and IL-10 were analyzed by RPA and normalized to the expression level of the housekeeping gene L32. The mRNAs that could be quantified are shown as fold increases compared with controls that are shown with dash line. Analyses of 3-8 dams or their litters ( 2 pups/dam) are shown as means \pm SEM. Statistically significant changes $(p<0.05)$ are denoted by $*$. further increased up to $8 \mathrm{~h}$, whereas at $16 \mathrm{dpc}$, these changes were smaller (Fig. 3A). Placental tissue responded rapidly to maternal LPS with increases in the expressions of IL- $1 \beta$, MIP-2, and IL-6 that tended to be more marked at the later stages of gestation (Fig. 3B).

The uterus showed a robust response as IL- $1 \beta$, MIP-2, IL-4, TNF- $\alpha$, IL-6, and IL-10 mRNAs were upregulated (Fig. 3C). In maternal lung, the expression of IL- $1 \beta$ and MIP- 2 increased strikingly after LPS (Fig. 3D).

Expression of TLR4 and TLR2 in fetal and maternal tissues. In fetal lung, both TLR4 and TLR2 showed significant downregulation by $8 \mathrm{~h}$ after LPS, response being stronger at later gestational age. TLRs in other fetal organs were unaffected. In fetal membranes, TLR4 and TLR2 mRNA levels tended to increase at $17 \mathrm{dpc}$. In placenta, the expression of TLR2 transiently increased.

In uterus and maternal lung, the expressions of TLR4 and TLR2 were affected by LPS (Fig. 4A, B). With the exception of the suppression of TLR4 expression in uterus at $16 \mathrm{dpc}$, mRNAs were increased.

Expression of collectins in fetal and maternal tissues. The expressions of SP-A and SP-D in fetal and maternal tissues revealed distinct responses (Fig. 5). At $17 \mathrm{dpc}$ in fetal lung, SP-A and SP-D expressions were strongly suppressed $8 \mathrm{~h}$ after LPS. At 16 dpc, only SP-A expression was detectable. In fetal membranes and in placenta, SP-A mRNA could not be detected, whereas SP-D expression was suppressed at $16 \mathrm{dpc}$. However, at $17 \mathrm{dpc}$, no significant response to LPS was detected.
In maternal tissues, there were no significant changes in the expression of collectins following LPS.

Immunohistochemistry. In fetal lung, interstitial macrophages contained TLR2, and there were no detectable changes in the number of macrophages after maternal LPS. However, in response to LPS, macrophages frequently appeared to be concentrated around the pulmonary vessels (Fig. 6A, B). TLR4 was barely detectable in fetal lung, regardless of LPS.

In placenta, $8 \mathrm{~h}$ after LPS, more granulocytes were detected in the spongiotrophoblast and giant cell layers than in the controls. TLR2 staining was evident in macrophages (Fig. 6C, $D, G)$. The most distinctive feature was the increase in TLR2positive macrophages in the labyrinthine vascular spaces $8 \mathrm{~h}$ after LPS treatment (Fig. $6 D$ versus $C$ ).

TLR2 and TLR4 were evident in some placental trophoblasts including giant trophoblasts. There were no remarkable changes in the TLR4 or TLR2 staining of cytotrophoblasts following the administration of LPS (Fig. $6 E-H$ ).

\section{DISCUSSION}

We have established a mouse model of the inflammatory response syndrome that leads to PTB of mostly live-born pups. This model mimics the transplacental transfer of the inflammatory signal from mother to fetus and is characterized by suppression of fetal innate immune response. Fetal lung was the focus of this study, because lung is the organ 

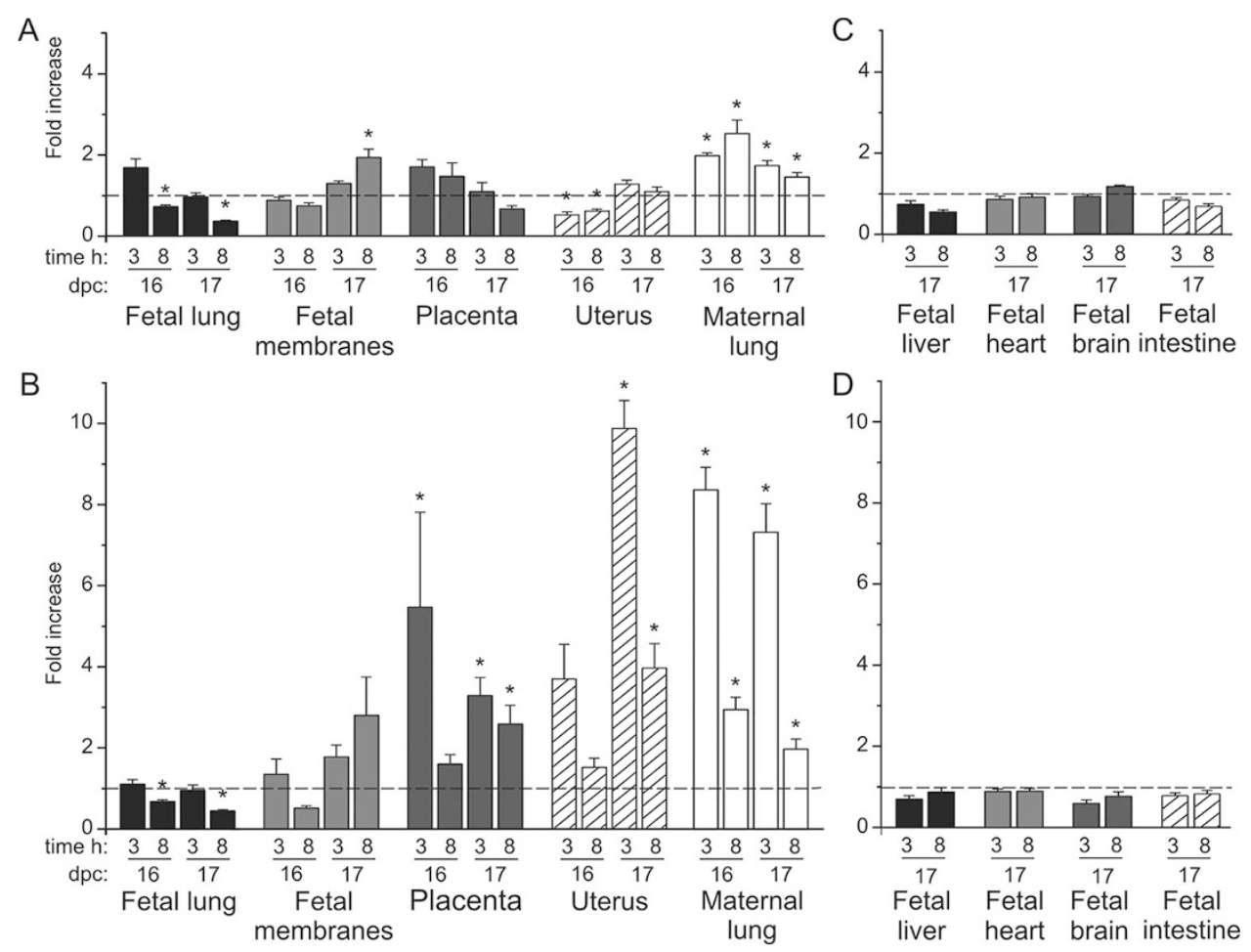

Figure 4. The expression levels of TLR4 $(A, C)$ and TLR2 $(B, D)$ in fetal and maternal tissues as a response to maternal LPS. Tissues were collected at $16(A, B)$ or $17 \mathrm{dpc}(A-D) 3$ or $8 \mathrm{~h}$ after PBS $(n=3-6)$ or LPS $(n=4-8)$ injection. The mRNA levels of TLR4 and TLR2 were analyzed by RPA and normalized to the expression level of the housekeeping gene L32. The mRNA levels are shown as fold increases compared with controls that are shown with dash line. Analyses of 3-7 dams or their litters (2 pups/dam) are shown as means \pm SEM. Statistically significant changes $(p<0.05)$ are denoted by $*$.
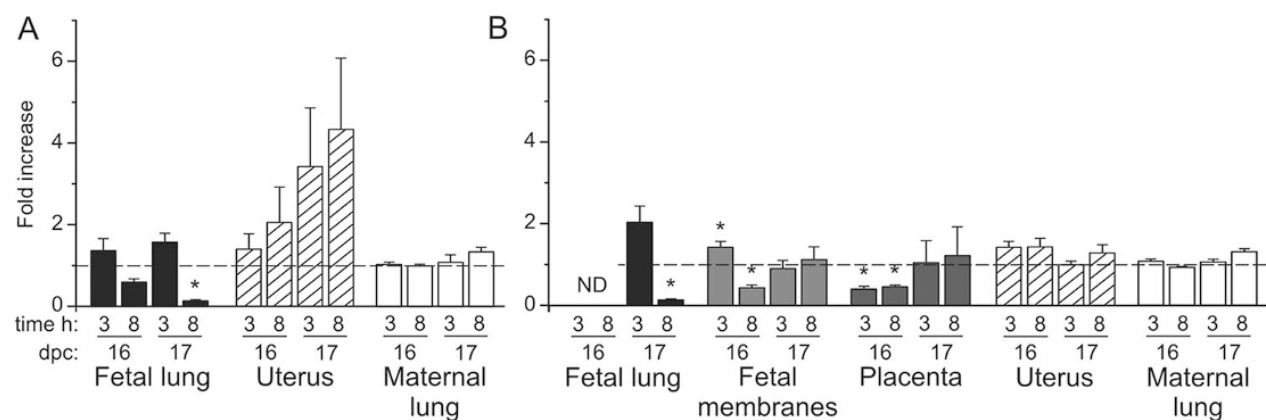

Figure 5. The expression levels of SP-A $(A)$ and SP-D $(B)$ in fetal and maternal tissues as a response to maternal LPS. Tissues were collected at 16 or 17 dpc 3 or $8 \mathrm{~h}$ after PBS ( $n=3-6)$ or LPS $(n=4-8)$ injection. The mRNA levels of SP-A and SP-D were analyzed by RPA and normalized to the expression level of the housekeeping gene L32. The mRNAs that could be quantified are shown as fold increases compared with controls that are shown with dash line. Analyses of 3-8 dams or their litters ( 2 pups/dam) are shown as means \pm SEM. Statistically significant changes $(p<0.05)$ are denoted by $*$. ND $=$ Not detected.

limiting survival after PTB and is a target for therapeutic interventions.

The outcome was dependent on the dose of LPS and also on the mouse strain, suggesting the influence of genetic constitution. Another interesting issue is the fetal survival during preterm labor. Most of the previously described models either do not address fetal survival or they produce PTBs of dead fetuses $(5,9,10)$. According to present evidence, the rate of fetal death associated with early gestation. No association of the fetal deaths with high proinflammatory cytokines or low antiinflammatory cytokines was detectable and the cytokine responses to LPS in placenta, fetal membranes, and amniotic fluid, were lower at $16 \mathrm{dpc}$ compared with $17 \mathrm{dpc}$. Therefore, the extent of proinflammatory response apparently did not explain the vulnerability of very immature fetuses. In human pregnancies, fetal death is associated with extremely PTB (26), which is consistent with the present data.

We show that the maternal inflammatory signal is rapidly transmitted from the maternal to the fetal compartment as the cytokine levels increase in fetal blood and in amniotic fluid. However, the early maternal and fetal inflammatory responses differed remarkably from each other and the maternal increases in cytokine and TLR expressions after LPS were much more robust than those in fetal assays. Only traces of LPS were detected in fetal blood and amniotic fluid after maternal LPS challenge (data not shown), suggesting cytokine/ chemokine-mediated signal transmission. However, the possibility of LPS-mediated inflammatory response in the fetus cannot be totally ruled out, as very small doses of LPS may cause inflammatory response.

The present model of transplacental inflammation differs from the ascending intrauterine inflammation that is the major preterm labor-producing inflammatory pathway in human pregnancies $(2,27)$. The intraamniotic inflammation is considered to be an extension of the ascending inflammation via cervix and decidual space characterized by activation of proinflammatory cytokines and accumulation of polymorphonuclear cells in fetal membranes and in fetal lung (28-30). Here, 


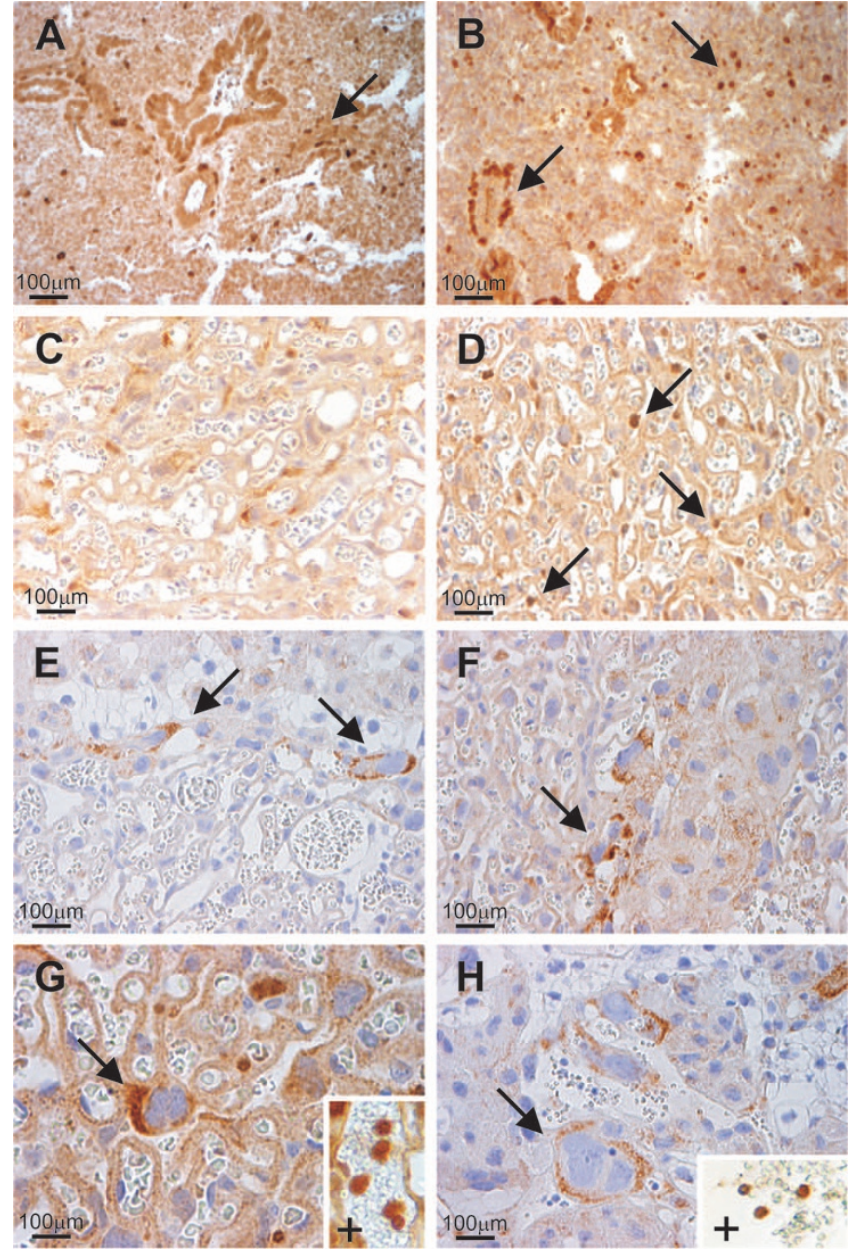

Figure 6. Immunostaining of lung $(A, B)$ and placenta $(C-H)$ with antiTLR2 $(A-D, G)$ and anti-TLR4 $(E, F, H)$ antibodies $8 \mathrm{~h}$ after PBS $(A, C, E)$ or maternal LPS $(B, D, F-H)$. Positively stained maternal blood monocytes are shown as insets in panels $G$ and $H$. In fetal lung, TLR2 positive macrophages tended to locate around the vessels after LPS ( $B$ vs. A). In labyrinthine placenta, the number of macrophages increased as a response to maternal LPS and they stained with TLR2 $(D$ vs. $C$ ), whereas TLR4 was undetectable. Some trophoblasts $(E, F)$ including giant trophoblasts $(H)$ stained with TLR4, and LPS had no detectable effect on immunostaining. Many placental trophoblasts also stained with TLR2 $(G)$, and LPS had no detectable effect on that staining. In each panel, TLR4 or TLR2 positive cells are indicated with arrows. Original magnification in all panels $\times 40$.

the main acute histologic changes were the accumulation of TLR2-positive macrophages in the labyrinthine area of placenta and in fetal lung their migration around pulmonary vessels. However, in fetal lung no changes in the total number of macrophages were detected.

Following maternal LPS, there were no significant changes in the expression levels of the cytokines in the fetal lung. Interestingly, the expression levels of SP-A, SP-D, TLR4, and TLR2 decreased significantly and the suppression increased toward term. This downregulation of SP and TLR expressions in fetal lung differs from the models of ascending inflammation in which LPS or IL- $1 \alpha$ is given into the amniotic fluid of rabbit or lamb and the inflammatory signal is entering the lung via the airway (28,31-33). A prominent increase in SP expression and an increase in surfactant components were observed $(31,32,34)$. Spontaneous PTBs were not reported, however.
SP-A and SP-D are involved both in innate immunity and in regulation of surfactant metabolism. Recent evidence suggests that SP-A administered into the amniotic fluid triggers the preterm labor process (23). The contribution of the fetal lung to preterm labor was proposed because surfactant components are secreted from the fetal lung into amniotic fluid. Here, we show that SP-A is expressed in uterus, whereas SP-D additionally was demonstrated in fetal membranes and as previously reported in placenta (35). Although the present results do not refute the theory of the involvement of the fetal lung in the labor process, the expression of SPs in placenta and fetal membranes is intriguing. The influence of LPS on the expression of collectins was different in uteroplacental tissue and in fetal lung. These findings are consistent with the possibility that collectins participate in host defense during respiratory adaptation, and that they may additionally be involved in modulation of the labor process.

To summarize, we have established an animal model to clarify the molecular mechanisms of adverse consequences of intrauterine inflammatory syndrome in PTB. However, the reproduction is species-specific, and the present results must be interpreted with caution. In human pregnancies, clinical chorioamnionitis and transplacental infections are also associated with PTB and adverse neonatal consequences as the increased risk of RDS $(36,37)$. Further research is in progress with aim to define the pathways of the inflammatory signals and transcription factors that control the harmful perinatal inflammatory events.

Acknowledgment. The authors are grateful to Maarit Haarala, Mirkka Ovaska, and Riitta Vuento for excellent technical assistance.

\section{REFERENCES}

1. Steer PJ 2006 The epidemiology of preterm labour — why have advances not equated to reduced incidence? BJOG 113:1-3

2. Romero R, Espinoza J, Kusanovic J, Gotsch F, Hassan S, Erez O, Chaiworapongsa T, Mazor M 2006 The preterm parturition syndrome. BJOG 113:17-42

3. Elovitz MA, Mrinalini C 2004 Animal models of preterm birth. Trends Endocrinol Metab 15:479-487

4. Hirsch E, Wang H 2005 The molecular pathophysiology of bacterially induced preterm labor: insights from the murine model. J Soc Gynecol Investig 12:145-155

5. Fidel PL Jr, Romero R, Wolf N, Cutright J, Ramirez M, Araneda H, Cotton DB 1994 Systemic and local cytokine profiles in endotoxin-induced preterm parturition in mice. Am J Obstet Gynecol 170:1467-1475

6. Elovitz MA, Wang Z, Chien EK, Rychlik DF, Phillippe M 2003 A new model for inflammation-induced preterm birth: the role of platelet-activating factor and Tolllike receptor-4. Am J Pathol 163:2103-2111

7. Rounioja S, Rasanen J, Glumoff V, Ojaniemi M, Makikallio K, Hallman M 2003 Intra-amniotic lipopolysaccharide leads to fetal cardiac dysfunction. A mouse mode for fetal inflammatory response. Cardiovasc Res 60:156-164

8. Rounioja S, Rasanen J, Ojaniemi M, Glumoff V, Autio-Harmainen H, Hallman M 2005 Mechanism of acute fetal cardiovascular depression after maternal inflammatory challenge in mouse. Am J Pathol 166:1585-1592

9. Buhimschi IA, Buhimschi CS, Weiner CP 2003 Protective effect of $\mathrm{N}$-acetylcysteine against fetal death and preterm labor induced by maternal inflammation. Am J Obstet Gynecol 188:203-208

10. Kaga N, Katsuki Y, Obata M, Shibutani Y 1996 Repeated administration of low-dose lipopolysaccharide induces preterm delivery in mice: a model for human preterm parturition and for assessment of the therapeutic ability of drugs against preterm delivery. Am J Obstet Gynecol 174:754-759

11. Reznikov LL, Fantuzzi G, Selzman CH, Shames BD, Barton HA, Bell H, McGregor JA, Dinarello CA 1999 Utilization of endoscopic inoculation in a mouse model of intrauterine infection-induced preterm birth: role of interleukin 1beta. Biol Reprod 60:1231-1238

12. Silver RM, Edwin SS, Trautman MS, Simmons DL, Branch DW, Dudley DJ, Mitchell MD 1995 Bacterial lipopolysaccharide-mediated fetal death. Production of a newly recognized form of inducible cyclooxygenase (COX-2) in murine decidua in response to lipopolysaccharide. J Clin Invest 95:725-731 
13. Kohmura Y, Kirikae T, Kirikae F, Nakano M, Sato I 2000 Lipopolysaccharide (LPS)-induced intra-uterine fetal death (IUFD) in mice is principally due to maternal cause but not fetal sensitivity to LPS. Microbiol Immunol 44:897-904

14. Sano H, Kuroki Y 2005 The lung collectins, SP-A and SP-D, modulate pulmonary innate immunity. Mol Immunol 42:279-287

15. Akira S, Uematsu S, Takeuchi O 2006 Pathogen recognition and innate immunity. Cell 124:783-801

16. Doyle SL, O'Neill LA 2006 Toll-like receptors: from the discovery of NFkappaB to new insights into transcriptional regulations in innate immunity. Biochem Pharmacol 72:1102-1113

17. Ojaniemi M, Liljeroos M, Harju K, Sormunen R, Vuolteenaho R, Hallman M 2006 TLR-2 is upregulated and mobilized to the hepatocyte plasma membrane in the space of Disse and to the Kupffer cells TLR-4 dependently during acute endotoxemia in mice. Immunol Lett 102:158-168

18. Wright JR 2005 Immunoregulatory functions of surfactant proteins. Nat Rev Immunol 5:58-68

19. Akiyama J, Hoffman A, Brown C, Allen L, Edmondson J, Poulain F, Hawgood S 2002 Tissue distribution of surfactant proteins A and D in the mouse. J Histochem Cytochem 50:993-996

20. Madsen J, Tornoe I, Nielsen O, Koch C, Steinhilber W, Holmskov U 2003 Expression and localization of lung surfactant protein A in human tissues. Am J Respir Cell Mol Biol 29:591-597

21. Leth-Larsen R, Floridon C, Nielsen O, Holmskov U 2004 Surfactant protein D in the female genital tract. Mol Hum Reprod 10:149-154

22. Miyamura K, Malhotra R, Hoppe HJ, Reid KB, Phizackerley PJ, Macpherson P, Lopez Bernal A 1994 Surfactant proteins A (SP-A) and D (SP-D): levels in human amniotic fluid and localization in the fetal membranes. Biochim Biophys Acta 1210:303-307

23. Condon JC, Jeyasuria P, Faust JM, Mendelson CR 2004 Surfactant protein secreted by the maturing mouse fetal lung acts as a hormone that signals the initiation of parturition. Proc Natl Acad Sci USA 101:4978-4983

24. Mendelson CR 2000 Role of transcription factors in fetal lung development and surfactant protein gene expression. Annu Rev Physiol 62:875-915

25. Hislop AA 2002 Airway and blood vessel interaction during lung development. J Anat 201:325-334
26. Rautava L, Lehtonen L, Peltola M, Korvenranta E, Korvenranta H, Linna M, Hallman M, Andersson S, Gissler M, Leipala J, Tammela O, Hakkinen U; PERFECT Preterm Infant Study Group 2007 The effect of birth in secondary- or tertiary-level hospitals in Finland on mortality in very preterm infants: a birth-register study. Pediatrics 119:e257-e263

27. Goldenberg RL, Culhane JF, Johnson DC 2005 Maternal infection and adverse fetal and neonatal outcomes. Clin Perinatol 32:523-559

28. Newnham JP, Moss TJ, Kramer BW, Nitsos I, Ikegami M, Jobe AH 2002 The fetal maturational and inflammatory responses to different routes of endotoxin infusion in sheep. Am J Obstet Gynecol 186:1062-1068

29. Watterberg KL, Demers LM, Scott SM, Murphy S 1996 Chorioamnionitis and early lung inflammation in infants in whom bronchopulmonary dysplasia develops. Pediatrics 97:210-215

30. Kallapur SG, Moss TJ, Ikegami M, Jasman RL, Newnham JP, Jobe AH 2005 Recruited inflammatory cells mediate endotoxin-induced lung maturation in preterm fetal lambs. Am J Respir Crit Care Med 172:1315-1321

31. Jobe AH, Newnham JP, Willet KE, Sly P, Ervin MG, Bachurski C, Possmayer F, Hallman M, Ikegami M 2000 Effects of antenatal endotoxin and glucocorticoids on the lungs of preterm lambs. Am J Obstet Gynecol 182:401-408

32. Bry K, Lappalainen U 2001 Intra-amniotic endotoxin accelerates lung maturation in fetal rabbits. Acta Paediatr 90:74-80

33. Hallman M, Lappalainen U, Bry K 1997 Clearance of intra-amniotic lung surfactant: uptake and utilization by the fetal rabbit lung. Am J Physiol 273:L55-L63

34. Bry K, Lappalainen U, Hallman M 1997 Intraamniotic interleukin-1 accelerates surfactant protein synthesis in fetal rabbits and improves lung stability after premature birth. J Clin Invest 99:2992-2999

35. Madsen J, Kliem A, Tornoe I, Skjodt K, Koch C, Holmskov U 2000 Localization of lung surfactant protein $\mathrm{D}$ on mucosal surfaces in human tissues. J Immunol 164:5866-5870

36. Alexander JM, Gilstrap LC, Cox SM, McIntire DM, Leveno KJ 1998 Clinical chorioamnionitis and the prognosis for very low birth weight infants. Obstet Gynecol 91:725-729

37. Andrews WW, Goldenberg RL, Faye-Petersen O, Cliver S, Goepfert AR, Hauth JC 2006 The Alabama Preterm Birth study: polymorphonuclear and mononuclear cell placental infiltrations, other markers of inflammation, and outcomes in 23- to 32-week preterm newborn infants. Am J Obstet Gynecol 195:803-808 